\title{
Cross-Talk Between Key Players in Patients with COVID-19 and Ischemic Stroke: A Review on Neurobiological Insight of the Pandemic
}

\author{
Pooja Kaushik ${ }^{1} \cdot$ Medha Kaushik $^{1} \cdot$ Sabiha Parveen $^{2} \cdot$ Heena Tabassum $^{3} \cdot$ Suhel Parvez $^{1}$ (D)
}

Received: 12 May 2020 / Accepted: 11 August 2020 / Published online: 19 August 2020

(C) Springer Science+Business Media, LLC, part of Springer Nature 2020

\begin{abstract}
The global pandemic of novel coronavirus disease 2019 (COVID-19) has taken the entire human race by surprise and led to an unprecedented number of mortalities worldwide so far. Current clinical studies have interpreted that angiotensin-converting enzyme 2 (ACE2) is the host receptor for severe acute respiratory syndrome-coronavirus 2 (SARS-CoV-2). In addition, ACE2 is the major component of the renin-angiotensin system. ACE2 deteriorates angiotensin II, a peptide that is responsible for the promotion of stroke. The downregulation of ACE2 further activates an immunological cascade. Thus, researchers need to explore and examine the possible links between COVID-19 and ischemic stroke (IS). Human ACE2 expression level and pattern in various tissues might be decisive for the vulnerability, symptoms, and treatment outcomes of the SARS-CoV-2 infection. The swift increase in the knowledge of SARS-CoV-2 has given creditable evidence that SARS-CoV-2 infected patients also encounter neurological deficits. As the SARS-CoV-2 binds to ACE2, it will hamper the activity of ACE2 in providing neuroprotection, especially in the case of stroke patients. Due to the downregulation of ACE2, the inflammatory response is activated in the ischemic penumbra. The COVID-19 pandemic has affected people with various pre-existing diseases, including IS, in such a way that these patients need special care and attention for their survival. Several clinical trials are currently ongoing worldwide as well as many other projects are in different stages of conceptualization and planning to facilitate the effective management of stroke patients with COVID-19 infection.
\end{abstract}

Keywords COVID-19 · Angiotensin-converting enzyme $2 \cdot$ Ischemic stroke $\cdot$ Renin-angiotensin system $\cdot$ Inflammatory response

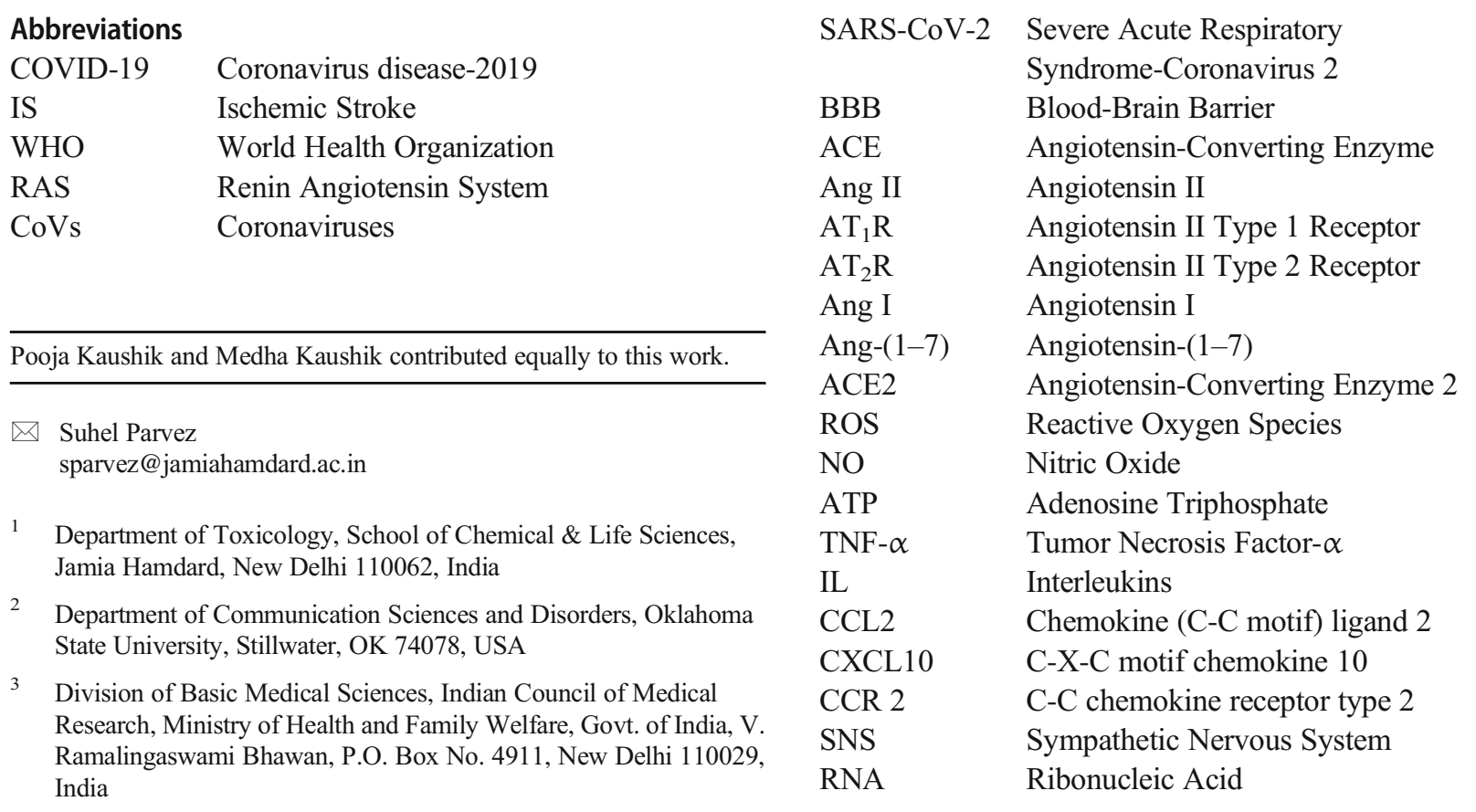




\section{Introduction}

COVID-19 is a serious pathological condition with an estimated reproductive number in the range of 2.2-3.5 [1] and highly infectious respiratory syndrome, including pneumonialike symptoms. The recently discovered SARS-CoV-2 is an extremely pathogenic virus [2]. Structurally, it is spherical and contains proteins in the form of spikes on its surface. These viruses contain positive sense single-stranded RNAs as their genome [3]. COVID-19 was declared as a pandemic by the World Health Organization (WHO) on 11th March 2020 due to its effect on the population worldwide [4]. As of 23rd July $2020,1,47,65,256$ have been confirmed to have this particular infection worldwide [4].

As the world is dealing with this pandemic, patients with other health ailments such as diabetes, hypertension, cancer, Parkinson's disease, and stroke are at a greater risk of getting infected with SARS-CoV-2 when compared with similaraged neurologically healthy adults. Among all the stroke cases, IS contributes to $80-85 \%$ of all cases globally [5]. It has been reported that lung infection is very common in IS patients, which, in turn, contributes to the high mortality rates [6]. Additionally, the immunological response and presence of the RAS considerably affect pulmonary immunity in the pathophysiology of IS as RAS is also present in pulmonary alveolar cells $[5,7,8]$. Recent reports have indicated that these related immunological responses are also encountered in the lungs of SARS-CoV-2-infected patients [4].

Based on the available knowledge and evidence regarding COVID-19 and stroke, we, therefore, attempt to present a consolidated review reflecting a degree of risk of getting infected with SARS-CoV-2 among stroke patients as well as the possible chances of stroke along with SARS-CoV-2 in infected individuals.

\section{Coronaviruses and Neurological Disorders}

In 1960, CoVs were discovered and classified under the family of Coronaviridae [3]. CoVs are further classified into two categories. The first category of CoVs comprises avian infectious bronchitis virus (IBV), transmissible gastroenteritis virus (TGEV), and porcine epidemic diarrhea virus (PEDV), which are the cause of the origin of in animals [3]. The second category includes CoVs, which can infect humans, and these CoVs have evolved rapidly due to their easy spread through human-to-human transmission. Some human CoVs discovered so far are severe acute respiratory syndrome-CoV (SARS-CoV) in 2002, HCoV-NL63 in 2004, HCoV-HKU1 in 2005, Middle East Respiratory Syndrome-CoV (MERS$\mathrm{CoV}$ ) in 2012, and the novel SARS-CoV-2 in 2019 [9, 10]. The SARS-CoV in 2002 resulted in 774 deaths out of 8098 cases ( $\sim 10 \%$ fatality) over 9 months, while MARS-CoV discovered in 2012 led to 862 deaths out of 2506 infections (
$35 \%$ fatality) till January 2020 [3]. Recently discovered SARS-CoV-2 has the lowest fatality rate $(\sim 3-4 \%)$, however, its human-to-human transmission is much easier when compared with the other CoVs. The easy human-to-human transmission has led to this becoming a global pandemic in a relatively short duration.

The human CoVs are not only responsible for respiratory infections, but they also induce other severe neurological disorders among infected patients. A case report by Lau et al. [11] identified a central nervous system infection in a 32-yearold SARS-CoV patient. Specifically, the patient's cerebrospinal fluid contained traces of SARS-CoV [11]. Various studies have also elucidated the association between MERS-CoV and neurological damage, subsequently causing intracranial hemorrhage [12], presence of virus titers in the thalamus, brainstem causing brain tissue damage [13], and severe neurological symptoms including stroke and encephalomyelitis among infected individuals [14].

The pandemic has rapidly spread across the globe after its origin in Wuhan, China, and most severely affecting countries including the United States of America, Italy, France, Germany, Spain, and Iran [9]. According to the weekly surveillance report of WHO from 29 June to 5 July 2020, $1,99,988$ deaths have been reported in the European region. While $22 \%$ of the total deaths have occurred in the United Kingdom, countries like Italy, and Spain recorded $17 \%$ and $14 \%$ of total deaths, respectively [15]. It is important to note that $95 \%$ of the total individuals who died due to COVID-19 in Italy and Spain were reported to have pre-existing health conditions. Major contributions to COVID deaths (66\%) were made by different cardiovascular disorders such as hypertension, heart attack, stroke, and other ailments, including diabetes, renal diseases, lung diseases, cancer, and neurological disorders. Another report confirmed that $9.6 \%$ of deaths among COVID-infected patients in Italy were associated with stroke-related complications [16]. As reported on 22nd July 2020 by the WHO, a total of 1,40,437 deaths have been reported in the United States of America, with approximately 4.04 million total SARS-CoV-2-infected patients [17]. The American Heart Association, in their guidelines, reported that $5.9 \%$ of total deaths were due to stroke-related complications following COVID-19 infections [18]. Additionally, a recent retrospective study in a New York Healthcare System also found a 7.5-fold higher rate of IS among COVID-19 patients when compared with influenza [19].

Further, a recent report from Wuhan, China, has elucidated the fact that $36 \%$ of total COVID-infected patients suffered from neurological symptoms, and $5.9 \%$ of such cases were observed to induce stroke among the SARS-CoV-2-infected patients [20]. Moreover, Li et al. (2020), in their single-center retrospective study, found that $4.6 \%$ of COVID-19-infected patients developed acute IS, and older patients with comorbidity are more prone to develop cerebrovascular disease [21]. 
Aging is the non-modifiable risk factor for IS as well as SARS-CoV-2 infection. It has been observed that patients with $\geq 65$ years are projected to develop IS and COVID infection $[22,23]$.

The treatment regime of COVID-19 has been observed in terms of possible benefits with the use of anti-stroke medications. The tissue plasminogen activator drug, such as Activase, is being considered as a potential therapy for SARS-CoV-2 by the pharma experts [24]. At present, no detrimental effects of anti-stroke drugs have been observed so far among the COVID-infected patients. Similarly, the antithrombotic effects of hydroxychloroquine have also been reported in several studies [25, 26]. In conclusion, the existing evidence suggests that there could be possible molecular links between SARS-CoV-2 pathogenesis and stroke.

\section{Renin-Angiotensin System and Risk of Ischemic Stroke}

RAS is accountable for the regulation of blood pressure, fluid, and electrolyte balance within the brain by upholding the homeostasis along with other involuntary functions [27]. The blood-brain barrier (BBB) physically separates the brain RAS from the peripheral tissues RAS. Within the brain RAS, all the components of classical RAS are synthesized, also known as the RAS element axis [28]. The axis specifically includes ACE-Ang II-AT $T_{1}$ R. Previous literature has reflected that the RAS element axis has been recognized to exhibit harmful events in the pathophysiology of IS [29].

The conventional pathway of RAS consists of two-step enzymatic processes. These include the cleavage of hepatic protein angiotensinogen by aspartyl protease renin to form Ang I, followed by the ACE-mediated hydrolysis of Ang I into Ang II. A meta-analysis of 47,000 subjects reflected that ACE insertion/deletion polymorphism might be a vulnerable hereditary factor for the IS [30]. Several studies have proved that the interaction of newly formed Ang II with its receptor (i.e., $\mathrm{AT}_{1} \mathrm{R}$ ) is involved in a high risk of thrombosis $[5,29]$. The other pathological conditions promoted by Ang II are atherosclerosis and endothelial dysfunction, thus escalating the overall menace of IS. The ischemic insult is typically followed by increased oxidative stress and decreased perfusion in the ischemic zone due to Ang II through $\mathrm{AT}_{1} \mathrm{R}$ along with induction in the inflammatory response [28, 31]. Taken together, over-activation of this conventional RAS pathway in the brain results in an amplified activity of the SNS and cardiovascular diseases, which ultimately enhance the risk for IS [27].

Recently, studies have revealed that the new RAS factors play counterpart roles in the pathophysiology of IS. This new axis of RAS in the brain comprises the human homolog of ACE, ACE2, Ang-(1-7), and Mas [28]. Physiologically, ACE2 mediates the hydrolysis of Ang II for the formation of
Ang-(1-7), a recognized ligand for the Mas receptor. Following ischemic injury, the activation of the ACE2Ang-(1-7)-Mas axis has been reported to have antithrombotic, anti-oxidative, and anti-inflammatory effects [5]. In comparison with Ang II, Ang-(1-7) is found to be neuroprotective. According to a study, the elevated levels of Ang-(1-7) can suppress the increased level of iNOS as well as proinflammatory cytokines in the ischemic hemisphere, thereby reflecting its neuroprotective effect [32].

In summary, the brain RAS exerts a decisive role in the pathogenic events of IS. In the ischemic penumbra, there will be inflammatory insults due to the activation of the brain RAS, which results in the progression of the immunological pathway.

\section{Immunological Response to Ischemic Stroke and Its Cross-talk with Pulmonary Infection}

During IS, the over-activation of $\mathrm{AT}_{1} \mathrm{R}$ signaling results in excitotoxicity. This, in turn, causes the release of glutamate stored in nerve cells in an extracellular matrix along with the generation of ROS and free radicals like NO. Due to these changes, the oxidative stress in the ischemic tissue is increased, which allows the BBB to become profoundly permeable [33], facilitating the influx of neutrophils and T cells in the ischemic region. Additionally, the increase of extracellular ATP results in the activation of microglia cells, which further activates the release of proinflammatory cytokines such as TNF- $\alpha$, interleukins IL-1 $\beta$, and IL-6 [34]. In ischemic tissue, these inflammatory cytokines further activate the apoptotic cascade resulting in severe cell death, inflammatory response, and rise of adhesion molecules on brain endothelial cells. All of these events result in leukocyte infiltration and subsequently cause sepsis and neurotoxicity. Along with these cytokines, IL-10 also has a critical role in the pathogenesis of IS [7]. Consequently, these indispensable inflammatory players become one of the possible therapeutic targets and biomarkers for IS [35].

Generally, in stroke, each cytokine has its response to the affected brain tissue. Elevated levels of IL-6 are associated with worsening of neurological symptoms, increased infarct volume, and poor stroke outcomes. IL-6 is also accountable for the release of prostaglandin E2 in the brain. This results in the activation of the hypothalamus ensuing in increased body temperature, which affects the infarct size, enhancement of inflammatory risk, and tissue damage following stroke [36]. Likewise, the upregulation of IL- $1 \beta$ is known to generate neurotoxicity in ischemic penumbra [7]. Various studies have demonstrated that increased levels of TNF- $\alpha$ are associated with neurotoxicity in blood serum and cerebrospinal fluid. However, there is contradictory literature that questions the association of TNF- $\alpha$ levels, increased infarct size, and deprived stroke results [7, 37]. After a stroke, the 
downregulation of IL-10 leads to increased infarct size, demonstrating the significance of IL-10 in the reduction of inflammatory response. Post-stroke, the increased levels of IL-10 reduce the activation of TNF- $\alpha$, therefore, diminishing the infarct progression [7, 35].

The post-ischemic inflammation cascade is a multicomponent process that involves chemoattractant, known as chemokines. Chemokines are the components of a superfamily of structurally related proinflammatory peptides that are involved in leukocyte infiltration into the inflammation site [38]. During ischemic insult, there is a release of chemokines CCL2 and CXCL10 in large amount. In the ischemic tissue, these chemokines are involved in leukocyte recruitment as well as disturbance of the BBB and leukocyte union to endothelial cells [39]. The expression of chemokines is directly proportional to the infarct size and advancement of IS. According to a study conducted by Dimitrijevic et al. [38] stroke progression was attenuated in the mice devoid of the chemokine receptor, CCR2 [38]. The levels of CCL2 and
CXCL10 were higher in IS patients in comparison with healthy patients when evaluated in a clinical setup [40].

Therefore, cytokines like IL-6, IL-1 $\beta$, TNF- $\alpha$, IL-10, and chemokines CCL2, and CXCL10 play a critical role in the progression and protection of IS. The extent of activation of the inflammatory cascade determines the succession or failure of stroke outcomes. One of the major pathological features of post-ischemic immunosuppression is a higher risk of pulmonary infections. Pulmonary infections, in turn, constitute the foremost acquisition event for stroke-associated pneumonia (SAP). SAP is often the main reason for mortality in severe IS subjects [6]. With the advancement of stroke complexity, local, as well as systemic immunological responses, may get triggered. A study conducted by Samary et al. [41] reported that focal IS strongly suppresses the phagocytic capability of alveolar macrophage, ensuing severe lung deterioration, and upregulation of IL-6 [41]. During IS, the maleficent cycle of brain-lung inflammation is observed. As described by Winklewski et al. [8] the SNS contributes to

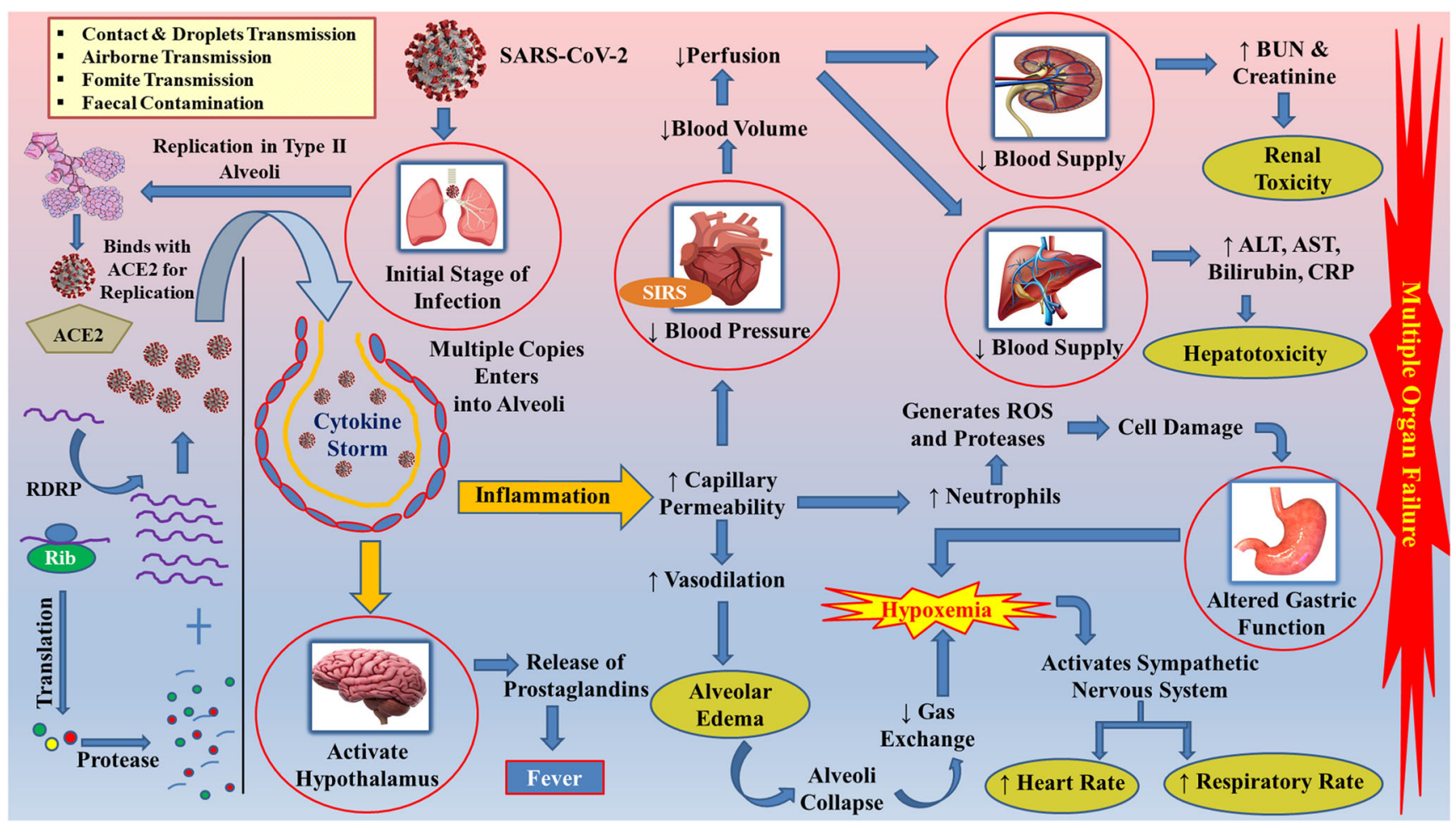

Fig. 1 Mechanistic overview of replication and pathophysiology of COVID-19. SARS-CoV-2 gets transmitted via faecal or droplet infection. Left panel: SARS-CoV-2 replicate in type II alveoli where it binds to the ACE2 receptor. By the process of transcription and translation, the singlestranded RNA of the SARS-CoV2 virus makes multiple copies with the help of host genetic material. Right panel: multiple copies of SARS$\mathrm{CoV} 2$ deteriorate the alveoli initializing the inflammatory cascades comprising interleukins and neutrophils. Activated interleukins act upon hypothalamus in the brain, affecting prostaglandins release, which is responsible for fever. Overactivation of interleukins increases the capillary permeability of alveoli, resulting in alveolar edema. Consequently, hypoxemia occurs with shortness of breath, affecting lung output. In this sequel, the partial pressure of oxygen decreases, affecting the heart rate and respiratory rate. When the infection remains unchecked, further inflammation severely affects the heart, which influences the blood supply to kidneys and liver distressing their functioning. Excessive inflammation generates an imprudent amount of reactive oxygen species that rigorously affect the gastric cavity. Collectively, the SARS-CoV-2 infection leads to multi-organ failure that may even lead to death. SIRS-systemic inflammatory response syndrome; RDRP-RNA-dependent RNA polymerase; Rib-Ribosome; BUN-Blood Urea Nitrogen; ALT-Alanine Transaminase; AST-Aspartate Aminotransferase; CRP-C-Reactive Protein; ROS-Reactive Oxygen Species; $\downarrow$ decrease; $\uparrow$ increase 


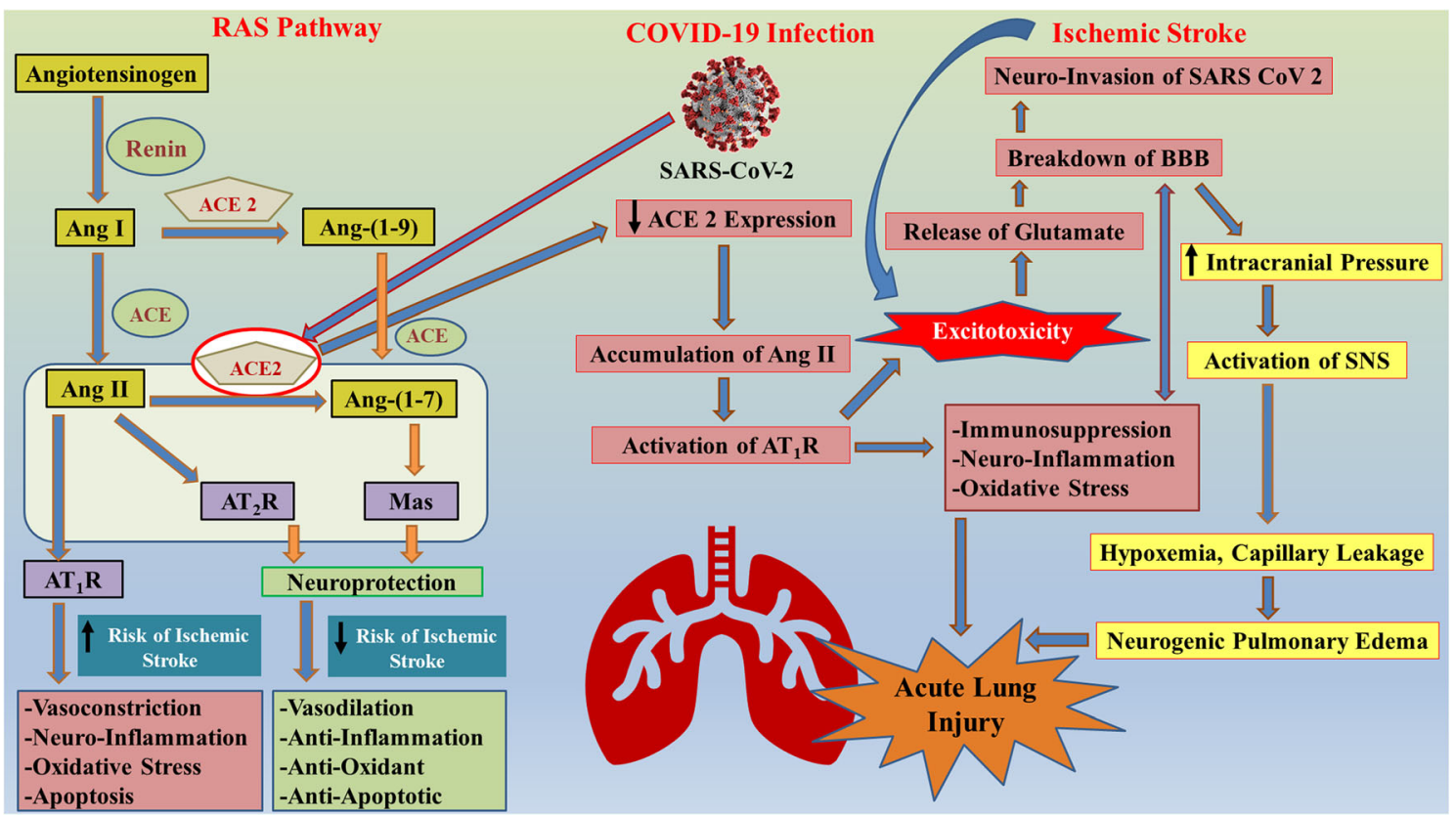

Fig. 2 Schematic diagram illustrating the role of RAS in cross-talk between ischemic stroke and SARS-CoV-2 infection. The brain RAS is regulator of physiological homeostasis and cerebrovascular disorders such as IS. Classical RAS elements include ACE, Ang II, and $\mathrm{AT}_{1} \mathrm{R}$. Angiotensinogen is hydrolyzed to Ang I by the aspartyl protease renin enzyme. Furthermore, ACE hydrolyzes the Ang I into Ang II. The interaction of newly formed Ang II with $\mathrm{AT}_{1} \mathrm{R}$ increases the risk of ischemic stroke as it results in an enhanced risk of thrombosis. On the other hand, the newly found RAS pathway exhibits the hydrolysis of Ang II in the presence of ACE2 to Ang-(1-7), which acts as a ligand for the Mas receptor. This new axis has anti-oxidative, anti-inflammatory, and antithrombotic activity, thus decreasing the risk of ischemic stroke. The binding of SARS-CoV-2 with ACE2 receptor in lungs leads to the

immunosuppression in this condition, which, in turn, increases the alveolar permeability and activates a local inflammatory response in the lungs and subsequently leads to lung infections [8]. It is important to note that, overall, there is a downregulation of ACE2 expression, which further results in accumulation in Ang II, thus activating the $\mathrm{AT}_{1} \mathrm{R}$ pathway and increased risk of IS. $\mathrm{AT}_{1} \mathrm{R}$ pathway activation leads to excitotoxicity, immunosuppression, neuroinflammation, and oxidative stress, finally resulting in acute lung injury. A secondary cascade is also activated due to excitotoxicity which results in the release of stored glutamate in brain cells, thus disrupting the BBB and allowing easy access of SARS-CoV-2 in brain. Breakdown of BBB also increases the intracranial pressure resulting in activation of SNS, hypoxia, capillary leakage, neurogenic pulmonary edema, and finally acute lung injury. Excitotoxicity is a crucial link between COVID19 and IS, as incidence of IS also results in excitotoxicity and breakdown of BBB, resulting in higher risk of comorbidity. $\downarrow$ Decrease; $\uparrow$ Increase

paucity of literature describing the mechanism of the immune cells and their role in pulmonary immunity in IS.

The available evidence implicates the strong relationships between inflammatory responses during and after IS as well

Table 1 List of key molecular players involved in COVID-19 infection and Ischemic Stroke. $\downarrow$ Downregulated; $\uparrow$ Upregulated

COVID-19 Ischemic Stroke References

Renin-Angiotensin System Expression

ACE2 Cell surface receptor for SARS-CoV-2 in host;

SARS-CoV-2 spike proteins binds to ACE2 in alveolar cells

$\mathrm{AT}_{1} \mathrm{R}$ signaling $\uparrow$ during COVID-19 infection $\uparrow$ decreases the chances of ischemic damage

$\downarrow$ increases the chances of ischemic stroke

$\uparrow$ produce neurotoxic effects
$5,28,42,43$

Immunological Response:

1. Cytokine expression

$\begin{array}{ll}\text { IL-1 } \beta & \uparrow \text { in lungs } \\ \text { IL-6 } & \uparrow \text { in lungs } \\ \text { IL-10 } & \uparrow \text { in lungs } \\ \text { TNF- } \alpha & \uparrow \text { in lungs }\end{array}$

$\uparrow$ in ischemic region

$4,7,34$

$\uparrow$ in ischemic region

$34,36,47$

$\uparrow$ in ischemic region

$4,7,34$

TNF- $\alpha$

$\uparrow$ in lungs

$\uparrow$ in ischemic region

$34,37,47$

2. Chemokine expression

$\begin{array}{ll}\text { CCL2 } & \uparrow \text { in lungs } \\ \text { CXCL10 } & \uparrow \text { in lungs }\end{array}$

$\uparrow$ in ischemic region

$38,39,47$

$\uparrow$ in ischemic region 
Table 2 Similarities in COVID19 infection and Ischemic Stroke

\begin{tabular}{llll}
\hline & COVID-19 & Ischemic Stroke & References \\
\hline Fever & Present & Sometimes present & 4,7 \\
Lung infection & Present & Possibility of development & 4,8 \\
ACE2 expression & Downregulated & Upregulated for neuroprotection & $5,42,43$ \\
AT $_{1}$ R signaling & Upregulated & Upregulation produce & $28,31,43$ \\
Cytokine expression (IL-1 $\beta$, & Upregulated & Upregulated & 4,7 \\
$\quad$ IL-6, IL-10, TNF- $\alpha$ etc.) & Upregulated & Upregulated & 4,7 \\
\hline
\end{tabular}

as the pulmonary health of humans. A comprehensive network of cross-talk between immunological reaction in stroke and alveolar macrophages exists, which ultimately influences the pulmonary functions. All of this also demonstrates a highrisk factor among IS patients for the advancement of different lung infections, including the current pandemic created by SARS-CoV-2.

\section{Cross-talk Between COVID-19 and Ischemic Stroke}

COVID-19 or novel coronavirus infection is highly dependent on the vulnerability of the host immunological responses. SARS-CoV-2 binds with the cell surface receptor protein ACE2 (Fig. 1). When there is SARS-CoV-2 infection, ACE2 gets down-regulated, which in turn, overexpresses Ang II and consequently activates $\mathrm{AT}_{1} \mathrm{R}$ signaling [42, 43]. This results in pulmonary permeability and unwarranted lung damage. Due to the SARS-CoV-2 mechanistic entry, the risk for COVID-19 infection increases due to the genetic propensity of ACE2 polymorphism and is subsequently associated with hypertension, diabetes mellitus, and IS [44].

Structurally, coronavirus contains a positive sense singlestranded RNA genome with the help of which they replicate, transcribe, and translate in the host cells and make multiple copies [45]. With the entry in the host cell, their viral single-stranded RNA moves freely into the host cytoplasm, initiating the translation process of two polyproteins, ensuing transcription of subgenomic RNAs, and viral genome replication [4]. As the number of viral copies increases, the upregulation of proinflammatory cytokines and chemokines results in a condition called cytokine release syndrome [46]. Clinically, such type of hyperimmune alterations is responsible for acute respiratory distress syndrome, comprising difficulty in breathing, cough, and pulmonary involvement in COVID patients. Generally, the most severe COVID infections have been identified with elevated levels of cytokines (IL-1 $\beta$, IL-6, IL-10, IL-2, IL-7, IL-8, and TNF- $\alpha$ ) and chemokines CXCL10 and CCL2 [47]. Such a pulmonary immune response is the probable influencer of COVID-19 infection among IS patients or vice versa.

According to a recent report, COVID-19 is associated with hemorrhagic lesions in the thalamus and medial temporal lobe.
The study also pointed out that the acute necrotizing encephalopathy in the patients can lead to BBB disruption [48, 49]. Pleasure et al. [50] also found that neurological symptoms such as stroke and depression were very common among severely affected COVID patients [50]. Another case study by Wang et al. [51] highlighted the effectiveness of tissue plasminogen activator administration, also used in the treatment of IS, to COVID-19 patients suffering from acute respiratory distress syndrome and respiratory failure [51]. Since the available evidence reflects the strong brain-lung interaction and immunological cross-talk among the two systems, the risk of COVID-19 infection among stroke patients, as well as the risk of stroke in COVID-19 patients, may be quite high (Fig. 2). Overall, although there is currently limited existing literature to elaborate the mechanism of the interplay of stroke and risk of pulmonary immunity damage, the available literature does suggest a high risk of being afflicted with COVID-19 among IS patients.

\section{Conclusion}

The current COVID-19 outbreak represents a medical crisis that is unavoidably distressing the management of preexisting complex conditions such as IS. As the pathophysiology of stroke comprises severe inflammation, stroke patients are more prone to higher infection risk than the general population. Both IS and COVID-19 have certain common molecular factors, as described (Tables 1 and 2). This cross-talk significantly exhibits as a high-risk contributor to COVID19 infection among stroke patients and induction of IS among COVID-19 patients. Thus, it is important to identify the factors that can help reduce the patient burden, poor quality of life, and possible complications.

Funding Information Ms. Pooja Kaushik received the Senior Research Fellowship from the University Grants Commission-Basic Science Research Program [File No. 25-1/2014-15(BSR)/7-91-2007(BSR)]. A Junior Research Fellowship from Cognitive Science Research Initiative (CSRI) EMR project supported by Department of Science and Technology, Govt. of India (No. DST/CSRI/2017/150[G]) provided to Ms. Medha Kaushik is acknowledged. Support from DST PURSE grant 
(No. SR/PURSE Phase 2/39[C]) and DST FIST (No. SR/FST/LS-I/2017/ $05[\mathrm{C}])$ are also acknowledged.

\section{Compliance with Ethical Standards}

Conflict of Interest The authors declare that they have no conflict of interest.

\section{References}

1. Zhang S, Diao MY, Yu W, Pei L, Lin Z, Chen D (2020) Estimation of the reproductive number of novel coronavirus (COVID-19) and the probable outbreak size on the Diamond Princess cruise ship: a data-driven analysis. Int J Infect Dis 93:201-204. https://doi.org/10. 1016/j.ijid.2020.02.033

2. Cui J, Li F, Shi ZL (2019) Origin and evolution of pathogenic coronaviruses. Nat Rev Microbiol 17:181-192. https://doi.org/10. 1038/s41579-018-0118-9

3. Ashour HM, Elkhatib WF, Rahman MM, Elshabrawy HA (2020) Insights into the recent 2019 novel coronavirus (Sars-coV-2) in light of past human coronavirus outbreaks. Pathogens 9:1-15. https://doi.org/10.3390/pathogens9030186

4. Favalli EG, Ingegnoli F, De Lucia O et al (2020) COVID-19 infection and rheumatoid arthritis: faraway, so close! Autoimmun Rev 19:102523. https://doi.org/10.1016/j.autrev.2020.102523

5. Jiang T, Gao L, Lu J, Zhang Y-D (2013) ACE2-Ang-(1-7)-Mas axis in brain: a potential target for prevention and treatment of ischemic stroke. Curr Neuropharmacol 11:209-217. https://doi. org/10.2174/1570159x11311020007

6. Farris BY, Monaghan KL, Zheng W, Amend CD, Hu H, Ammer AG, Coad JE, Ren X et al (2019) Ischemic stroke alters immune cell niche and chemokine profile in mice independent of spontaneous bacterial infection. Immun Inflamm Dis 7:326-341. https://doi.org/ 10.1002/iid3.277

7. Doll DN, Barr TL, Simpkins JW (2014) Cytokines: their role in stroke and potential use as biomarkers and therapeutic targets. Aging Dis 5:294-306. https://doi.org/10.14336/AD.2014.0500294

8. Winklewski PJ, Radkowski M, Demkow U (2014) Cross-talk between the inflammatory response, sympathetic activation and pulmonary infection in the ischemic stroke. J Neuroinflammation 11: 4-11. https://doi.org/10.1186/s12974-014-0213-4

9. Qiu Y, Zhao YB, Wang Q, Li JY, Zhou ZJ, Liao CH, Ge XY (2020) Predicting the angiotensin converting enzyme 2 (ACE2) utilizing capability as the receptor of SARS-CoV-2. Microbes Infect 2:221-225. https://doi.org/10.1016/j.micinf.2020.03.003

10. Kruse RL (2020) Therapeutic strategies in an outbreak scenario to treat the novel coronavirus originating in Wuhan, China. F1000Res 9:72. https://doi.org/10.12688/f1000research.22211.1

11. Lau K, Yu W, Chu C et al (2004) Infection by SARS Coronavirus. Emerg Infect Dis 10(2):342-344. https://doi.org/10.3201/eid1002. 030638

12. Al-Hameed FM (2017) Spontaneous intracranial hemorrhage in a patient with Middle East respiratory syndrome corona virus. Saudi Med J 38:196-200. https://doi.org/10.15537/smj.2017.2.16255

13. Li K, Wohlford-Lenane C, Perlman S, Zhao J, Jewell AK, Reznikov LR, Gibson-Corley KN, Meyerholz DK et al (2015) Middle east respiratory syndrome coronavirus causes multiple organ damage and lethal disease in mice transgenic for human dipeptidyl peptidase 4. J Infect Dis 212:712-722. https://doi.org/ 10.1093/infdis/jiv499

14. Arabi YM, Harthi A, Hussein J, Bouchama A, Johani S, Hajeer AH, Saeed BT, Wahbi A et al (2015) Severe neurologic syndrome associated with Middle East respiratory syndrome corona virus
(MERS-CoV). Infection 43:495-501. https://doi.org/10.1007/ s15010-015-0720-y

15. (2020) COVID-19 weekly surveillance report. 2020:2020

16. 74783607. accessed 11-15th April, 2020. @ www.businessinsider. in

17. Culp WC (2020) Coronavirus disease 2019. A A Pract 14:e01218. https://doi.org/10.1213/xaa.0000000000001218

18. Lyden P (2020) Temporary emergency guidance to US stroke centers during the COVID-19 pandemic on behalf of the AHA/ASA Stroke Council Leadership. Stroke 10. https://doi.org/10.1161/ STROKEAHA.120.030023

19. Yaghi S, Ishida K, Torres J, Mac Grory B, Raz E, Humbert K, Henninger N, Trivedi T et al (2020) SARS-CoV-2 and stroke in a New York Healthcare System. Stroke 51:2002-2011. https://doi. org/10.1161/strokeaha. 120.030335

20. 3e23d100cd5cacbcf16cf4b56fe2eb158b84fd85. accessed 11-15th April, 2020. @www.neurologyadvisor.com

21. Li Y, Li M, Wang M, Zhou Y, Chang J, Xian Y, Wang D, Mao L et al (2020) Acute cerebrovascular disease following COVID-19: a single center, retrospective, observational study. Stroke Vasc Neurol:1-6. https://doi.org/10.1136/svn-2020-000431

22. Shi Y, Wang Y, Shao C, Huang J, Gan J, Huang X, Bucci E, Piacentini $M$ et al (2020) COVID-19 infection: the perspectives on immune responses. Cell Death Differ 27:1451-1454. https:// doi.org/10.1038/s41418-020-0530-3

23. Yousufuddin M, Young N (2019) Aging and ischemic stroke. Aging (Albany NY) 11:2542-2544. https://doi.org/10.18632/ aging.101931

24. experts-suggest-roche-s-activase-as-a-potential-covid-19drug. accessed 11-15th April, 2020. @ www.fiercepharma.com

25. Schmidt-Tanguy A, Voswinkel J, Henrion D, Subra JF, Loufrani L, Rohmer V, Ifrah N, Belizna C (2013) Antithrombotic effects of hydroxychloroquine in primary antiphospholipid syndrome patients. J Thromb Haemost 11:1927-1929. https://doi.org/10.1111/ jth. 12363

26. Belizna C (2015) Hydroxychloroquine as an antithrombotic in antiphospholipid syndrome. Autoimmun Rev 14:358-362. https:// doi.org/10.1016/j.autrev.2014.12.006

27. Huber G, Schuster F, Raasch W (2017) Brain renin-angiotensin system in the pathophysiology of cardiovascular diseases. Pharmacol Res 125:72-90. https://doi.org/10.1016/j.phrs.2017.06. 016

28. Xu P, Sriramula S, Lazartigues E (2011) ACE2/ANG-(1-7)/Mas pathway in the brain: The axis of good. Am J Physiol Regul Integr Comp Physiol 300:R804-R817. https://doi.org/10.1152/ ajpregu.00222.2010

29. Mogi M, Horiuchi M (2013) Effect of angiotensin II type 2 receptor on stroke, cognitive impairment and neurodegenerative diseases. Geriatr Gerontol Int 13:13-18. https://doi.org/10.1111/j.14470594.2012.00900.x

30. Zhao J, Qin X, Li S, Zeng Z (2014) Association between the ACE I/ D polymorphism and risk of ischemic stroke: an updated metaanalysis of 47,026 subjects from 105 case-control studies. J Neurol Sci 345:37-47. https://doi.org/10.1016/j.jns.2014.07.023

31. Horiuchi M, Mogi M (2011) Role of angiotensin II receptor subtype activation in cognitive function and ischaemic brain damage. $\mathrm{Br} \mathrm{J}$ Pharmacol 163:1122-1130. https://doi.org/10.1111/j.1476-5381. 2010.01167.x

32. Sierra H, Cordova M, Chen CSJ, Rajadhyaksha M (2015) Confocal imaging-guided laser ablation of basal cell carcinomas: an ex vivo study. J Invest Dermatol 135:612-615. https://doi.org/10.1038/jid. 2014.371

33. Chen T, Dai SH, Li X, Luo P, Zhu J, Wang YH, Fei Z, Jiang XF (2018) Sirt1-Sirt3 axis regulates human blood-brain barrier permeability in response to ischemia. Redox Biol 14:229-236. https://doi. org/10.1016/j.redox.2017.09.016 
34. Tuttolomondo A, Di Raimondo D, di Sciacca R et al (2008) Inflammatory cytokines in acute ischemic stroke. Curr Pharm Des 14:3574-3589. https://doi.org/10.2174/138161208786848739

35. Nayak AR, Kashyap RS, Purohit HJ, Kabra D, Taori GM, Daginawala HF (2009) Evaluation of the inflammatory response in sera from acute ischemic stroke patients by measurement of IL-2 and IL-10. Inflamm Res 58:687-691. https://doi.org/10.1007/ s00011-009-0036-4

36. Lambertsen KL, Biber K, Finsen B (2012) Inflammatory cytokines in experimental and human stroke. J Cereb Blood Flow Metab 32: 1677-1698. https://doi.org/10.1038/jcbfm.2012.88

37. Lasek-Bal A, Jedrzejowska-Szypulka H, Student S et al (2019) The importance of selected markers of inflammation and blood-brain barrier damage for short-term ischemic stroke prognosis. J Physiol Pharmacol 70:209-217. https://doi.org/10.26402/jpp.2019.2.04

38. Dimitrijevic OB, Stamatovic SM, Keep RF, Andjelkovic AV (2007) Absence of the chemokine receptor CCR2 protects against cerebral ischemia/reperfusion injury in mice. Stroke 38:13451353. https://doi.org/10.1161/01.STR.0000259709.16654.8f

39. Kuboyama K, Harada H, Tozaki-Saitoh H, Tsuda M, Ushijima K, Inoue K (2011) Astrocytic P2Y1 receptor is involved in the regulation of cytokine/chemokine transcription and cerebral damage in a rat model of cerebral ischemia. J Cereb Blood Flow Metab 31: 1930-1941. https://doi.org/10.1038/jcbfm.2011.49

40. Amin M, Vakilian A, Mahmoodi MH, Hassanshahi G, Falahati pour SK, Dolatabadi MR, Nadimi AE (2017) İskemik inmeli hastalarda 1, 9 ve 10 CXC-kemokin ligandlarının dolaşımdaki seviyelerinde artış. Eurasian J Med 49:92-96. https://doi.org/10. 5152/eurasianjmed.2017.17022

41. Samary CS, Ramos AB, Maia LA, Rocha NN, Santos CL, Magalhães RF, Clevelario AL, Pimentel-Coelho PM et al (2018) Focal ischemic stroke leads to lung injury and reduces alveolar macrophage phagocytic capability in rats. Crit Care 22:1-11. https://doi.org/10.1186/s13054-018-2164-0

42. Danser AHJ, Epstein M, Batlle D (2020) Renin-angiotensin system blockers and the COVID-19 pandemic. Hypertension 75:1-4. https://doi.org/10.1161/hypertensionaha.120.15082

43. Hoffmann M, Kleine-Weber H, Schroeder S et al (2020) SARSCoV-2 cell entry depends on ACE2 and TMPRSS2 and is blocked by a clinically proven protease inhibitor. Cell:1-10. https://doi.org/ 10.1016/j.cell.2020.02.052
44. Fang L, Karakiulakis G, Roth M (2020) Are patients with hypertension and diabetes mellitus at increased risk for COVID-19 infection? Lancet Respir Med 8:e21. https://doi.org/10.1016/S22132600(20)30116-8

45. Guo YR, Cao QD, Hong ZS, Tan YY, Chen SD, Jin HJ, Tan KS, Wang DY et al (2020) The origin, transmission and clinical therapies on coronavirus disease 2019 (COVID-19) outbreak - an update on the status. Mil Med Res 7:11. https://doi.org/10.1186/s40779020-00240-0

46. Mehta P, McAuley DF, Brown M, Sanchez E, Tattersall RS, Manson JJ, HLH Across Speciality Collaboration, UK (2020) COVID-19: consider cytokine storm syndromes and immunosuppression. Lancet 395:1033-1034. https://doi.org/10.1016/S01406736(20)30628-0

47. Wan S, Yi Q, Fan S et al (2020) Characteristics of lymphocyte subsets and cytokines in peripheral blood of 123 hospitalized patients with 2019 novel coronavirus pneumonia (NCP). MedRxiv. https://doi.org/10.1101/2020.02.10.20021832

48. Poyiadji N, Shahin G, Noujaim D et al (2020) COVID-19-associated acute hemorrhagic necrotizing encephalopathy: CT and MRI features. Radiology:201187. https://doi.org/10.1148/radiol. 2020201187

49. Joob B, Wiwanitkit V (2020) Hemorrhagic problem among the patients with COVID-19: clinical summary of 41 Thai infected patients. Clin Appl Thromb Hemost 26:1076029620918308. https://doi.org/10.1177/1076029620918308

50. Pleasure SJ, Green AJ, Josephson SA (2020) The spectrum of neurologic disease in the severe acute respiratory syndrome coronavirus 2 pandemic infection: neurologists move to the frontlines. JAMA Neurol. 77(6):679-680. https://doi.org/10.1001/ jamaneurol.2020.1065

51. Wang J, Hajizadeh N, Moore EE, McIntyre RC, Moore PK, Veress LA, Yaffe MB, Moore HB et al (2020) Tissue plasminogen activator (tPA) treatment for COVID-19 associated acute respiratory distress syndrome (ARDS): a case series. J Thromb Haemost 18: 1752-1755. https://doi.org/10.1111/jth.14828

Publisher's Note Springer Nature remains neutral with regard to jurisdictional claims in published maps and institutional affiliations. 